\title{
La lectura de lo breve o de cómo la minificción llegó al aula
}

DOI: https://doi.org/10.32870/dse.v0i11.273

Perla Cristal Hermosillo Núñez*

Resumen: Este trabajo presenta un conciso recorrido por las diferentes acepciones de lectura. Se reflexiona acerca de cómo las nuevas tecnologías han transformado las prácticas lectoras. En este contexto se resaltan las características de la minificción en afinidad con las nuevas formas de leer y la viabilidad de su lectura en el aula. Palabras clave: lectura, minificción, narrativa, nuevas tecnologías, lectura en el aula.

Abstract: This paper presents a brief overview of the different meanings of reading. There is a reflection on how new technologies have transformed the reading practices. In this context, the characteristics of the minifiction are highlighted in affinity with new ways of reading and viability of reading in the classroom. Key words: reading, minifiction, narrative, new technologies, classroom reading.

La lectura y sus posibilidades de estudio son temas que han sido investigados desde diferentes perspectivas: a partir del libro de texto, el fomento a la lectura, la comprensión lectora, etcétera (Macías Andere y López Hernández, 2013). En la actualidad se ubica como un tema de investigación que ha tomado mayor importancia por la presencia de los medios electrónicos, los cuales han modificado las formas tradicionales de leer al tener como soporte una plataforma virtual (McInerney, 2005).

Así, las posibilidades de lectura se relacionan con la virtualidad y el acceso a la información en el momento y lugar en que cada persona decida. En el caso del ámbito escolar, los estudiantes buscan textos en internet, de preferencia cortos, para cubrir sus necesidades académicas. En la red existen resúmenes, sinopsis, entre otros tipos de textos, que los alumnos utilizan para realizar sus tareas con más facilidad y en menor tiempo.

Este contexto funciona como una panorámica donde se resalta la importancia de la brevedad textual desde el ámbito de las nuevas tecnologías. Estas circunstancias favorecen la lectura de los textos literarios llamados minificciones: " "escritos con dominante narrativa cuya extensión es menor a 200 palabras" (Zavala, 2006: 225). La difusión de los minicuentos es beneficiada por las redes sociales como facebook y twitter, lo cual permite la proximidad del estudiante a su lectura.

¿A qué se le llama lectura? ¿Qué significa leer en la actualidad? ¿Cómo se relaciona la minificción con las prácticas lectoras contemporáneas? ¿Cuáles son las características de la minificción que hacen viable su lectura en el aula? El propósito general de este ensayo es reflexionar acerca de

* Maestría en Literatura Mexicana, Universidad de Guadalajara; estudiante de Doctorado en Educación. Av. Guadalajara 2590 int. 37, Col. Altus Quintas. Tel., 305561 58. Correo electrónico: perlacristalorama@gmail.com

${ }^{1} \_\mathrm{Me}$ referiré a este tipo de textos como minificciones y minicuentos 
Mónica Almeida López, Rachel Garcíaeres, Reynaga, Hilde Aquino, Teresa Orozco. Colaboradores: Pablo Silva Villalever y Víctor Montero Gaytán

cómo las prácticas lectoras se han transformado en el contexto de las nuevas tecnologías, lo cual favorece la lectura de minicuentos en el aula.

\section{Las acepciones de lectura}

Hay quienes consideran la lectura como arte (Nieto, 2003). Resaltan las emociones, los pensamientos y la sensibilidad durante el proceso de decodificación de la lengua escrita. Un texto tiene tantas interpretaciones como lectores, las cuales dependen de los sentimientos individuales provocados por el escrito. Por lo tanto es un proceso único e individual, incomprensible para otros, pues cada persona vive su propia forma de leer.

La lectura también ha sido conceptualizada como una experiencia. Su definición depende del interés manifestado por el sujeto ante esta habilidad, varía de acuerdo con cada persona y trasciende el proceso físico que implica utilizar los ojos y el cerebro. Cada individuo se encuentra en una situación única y establece un vínculo profundo con el texto. A esta situación se le llama experiencia porque ocurre de manera interna. Las experiencias de lectura sólo pueden explicarse a partir de la propia subjetividad. Los conceptos de experiencia, realidad y significado son indefinibles y se les atribuye un sentido dependiendo del contexto específico donde se realice la experiencia lectora (Smith, 1990).

Larrosa (2003) señala que la lectura es una experiencia donde predomina la sensibilidad. El lector experimenta diversos sentimientos y emociones, únicos e irrepetibles, cuando se encuentra en contacto con el texto literario. Éstos dependen del estado de ánimo del lector y la singularidad de la obra literaria, elementos indispensables en la conformación de esa sensibilidad.

Otros la definen como un conducto para la construcción del espacio personal, íntimo y de carácter privado (Petit, 2001), lo cual es consecuencia de la interiorización que cada sujeto hace del texto. Vaca Uribe (2003) también estudia este proceso. Él analiza la forma en que el individuo aborda el texto y lo interpreta. Así, entre más experiencia lectora tenga el sujeto, aumenta la capacidad de procesar unidades textuales.

Córdova, Ochoa y Rizk coinciden en que la lectura "desarrolla la capacidad de juicio, el análisis, la concentración, el espíritu crítico y estimula la recreación de la fantasía y el desarrollo de la creatividad" (Córdova, Ochoa y Rizk, 2009: 161). Desde esta visión, el lector aumenta su bagaje cultural mediante el conocimiento e información proporcionados por la lectura y además incentiva el uso de la imaginación, lo cual se traduce en la representación de su mundo de formas alternativas.

Algunos autores más indican que la comprensión es el propósito de la lectura: "consiste en la ampliación del dominio lingüístico desde la mera conversación hasta formas cada vez más formalizadas y abstractas" (Colomer, 1997: 8). Para llegar a la comprensión, el individuo aprende a distinguir la estructura superficial y la estructura profunda del texto, lo cual le permite otorgar un significado al escrito a través de la información subyacente en las palabras (Córdova, Ochoa y Rizk, 2009). Además, la creación de diferentes circunstancias de lectura es necesaria para originar 
Los programas de investigación, promoción e intervención social para la mejora de habilidfades de lectocomprensión en la Región Ameca Jalisco en CUValles, Universidad de Guadalajara

interpretaciones diversas del escrito. Los estímulos proporcionados por diferentes vías como el material didáctico o la mediación del profesor son determinantes para entender los textos de múltiples formas.

Caldera, Escalante y Terán definen la lectura como "un proceso complejo, en el cual el lector, con su experiencia previa, reconstruye el sentido del texto y lo incorpora a su propia realidad" (Caldera, Escalante y Terán, 2011: 453). Esto implica que el lector realiza la vinculación entre sus conocimientos previos y la información nueva que se le presenta para adaptarla a su contexto inmediato, representado por el escrito con el cual contacta. Estos autores también resaltan la presencia del razonamiento, los procesos cognitivos básicos y la aplicación de procesos cognitivos superiores durante la lectura comprensiva, aspectos imprescindibles en las investigaciones acerca de este tema.

La lectura también ha sido definida como la construcción del significado. El acto de leer comienza como una actividad personal en la cual los sujetos presentan diversas formas de recepción según el tema y el tipo de texto presentado (Solé, 2007). Esta fase individual del proceso de lectura se conjunta con la mediación del contexto, el cual funge como marco de interpretación que permite la construcción del significado. Sin embargo, el lector es el participante con mayor relevancia porque es él quien aplica sus recursos y habilidades para interpretar la información de un escrito.

Al respecto Goodman (1989) afirma que la lectura es inexistente sin significado y para llegar a él es necesario que el individuo viva un proceso. Desde esta perspectiva, la lectura es un proceso en donde el pensamiento y el lenguaje se encuentran en constantes transformaciones cuando el lector intenta dar sentido al texto para construir el significado.

Las nuevas literacidades contemplan la lectura y la escritura como un continuo, donde lo social y lo cultural interactúan para conformar prácticas sociales. Yubero Jiménez y Larrañaga Rubio sostienen que: "Aunque leer es una conducta individual, posee un significado social y cultural..." (Yubero y Larrañaga, 2010: 9). Esta situación implica el estudio de una dimensión social relacionada con las normas, creencias y significados compartidos que tienen los sujetos acerca de la lectura y su comportamiento ante la misma.

González, Guízar, Sepúlveda y Villaseñor (2003) resaltan algunos de los elementos que intervienen en la lectura como proceso individual y social: curiosidad, motivación y necesidad personal y social de construir su propio conocimiento. La lectura no es una habilidad innata en el sujeto aunque dependa en gran medida de él, sino que estriba en los objetivos personales y los agentes externos influyentes en las diversas maneras de leer.

Las acepciones de lectura son diversas: como proceso individual, como experiencia de lectura, como comprensión del mensaje, como construcción del significado. La definición más relevante para este ensayo es la referente a la lectura como práctica social y cultural, la cual se construye a partir de las aportaciones en conjunto de los integrantes de un grupo. 


\section{Nuevas formas de leer}

El surgimiento de nuevas formas de comunicación ha diversificado los modos de leer y con ello se han presentado otras maneras de analizar la literacidad, la cual es considerada como una serie de competencias que permiten a un sujeto "producir, gestionar, editar, recibir y analizar información en un determinado contexto para transformarla en conocimiento" (Caro Salcedo y Arbeláez Echeverri, 2009: 5). Estas habilidades son partes fundamentales de la lectura y la escritura, consideradas procesos continuos no excluyentes entre sí, sino complementarios en todas las etapas de alfabetización y en los encuentros con diferentes tipos de textos en diversos medios.

La lectura y la escritura son prácticas sociales definidas como actividades humanas determinadas por "las condiciones sociales e históricas particulares que configuran las maneras de leer, los usos de la lectura, los sentidos y sus posibles significados" (Lemos Vóvio, 2008: 13). Además, se incluyen las formas de enseñanza-aprendizaje de la lectura así como los materiales que pueden ser leídos. Desde esta perspectiva, la lectura consiste en que los sujetos interpreten y den sentido a los textos como resultado de la interacción con otros.

Las nuevas formas de enseñar y aprender como resultado de la era digital se representan de múltiples maneras. Un ejemplo de ello es la literacidad electrónica, definida como la capacidad para codificar y decodificar mensajes en los medios electrónicos (Caro Salcedo y Arbeláez Echeverri, 2009).

En este contexto encontramos que "Leer ya no es tanto leer un libro literario o de ensayo de principio a fin. Hay nuevos modos de leer, favorecidos por la multiplicación de materiales impresos y soportes tecnológicos para los textos" (Sanjuán Álvarez, 2011: 95). De este modo, la aparición del texto electrónico representa la llegada de nuevas realidades textuales y, con ellas, nuevas formas de leer como producto de representaciones sociales y culturales que guían su función y su propósito.

Desde este enfoque el lector posee una percepción diferente del texto porque tiene el control sobre lo que desea leer y de qué manera hacerlo. Así, la lectura se convierte en un proceso que consiste en "romper el vínculo inmediatamente visible que une el texto y el objeto donde se encuentra inscrito" (Chartier, 2000: 52). Así, la lectura no está representada por la contigüidad propia del texto impreso sino por la elección fragmentaria y desordenada según los intereses y necesidades del lector.

Desde el ámbito de las nuevas tecnologías, las transformaciones en las prácticas lectoras se inclinan hacia los textos breves (Zavala, 2006). En éstos predomina lo fragmentario y lo fugaz, características representativas de la forma de vida contemporánea.

\section{Pertinencia de la lectura de minificciones en el aula}

En la mente del lector existen efectos producidos por la lectura de obras literarias. Éstas contienen elementos que liberan esas respuestas porque su forma de narrar las historias se centra en trabajar 
Los programas de investigación, promoción e intervención social para la mejora de habilidfades de lectocomprensión en la Región Ameca Jalisco en CUValles, Universidad de Guadalajara

de manera adecuada la trama y el relato. Para ello debe existir un equilibrio entre los personajes, las metas, los ambientes y los medios expuestos en la obra literaria (Bruner, 2012).

El relato de un minicuento contiene la acción, la cual abarca los elementos que construyen una obra narrativa, como la intención y la meta; también presenta la conciencia: saber, pensar o sentir por parte de los que intervienen en la acción (Bruner, 2012: 25). Desde esta perspectiva, la realidad mental se encuentra en la narración porque el autor coloca en la historia diferentes circunstancias y personajes para lograr un efecto en el receptor.

Zavala identifica seis características de la minificción: brevedad, diversidad, complicidad, fractalidad, fugacidad y virtualidad. La brevedad es una característica de este género que proporciona un gran impacto en los receptores y lo convierte en una forma de la literatura más cercana a los alumnos. "El espacio de una página puede ser suficiente, paradójicamente, para lograr la mayor complejidad literaria, la mayor capacidad de evocación..." (Zavala, 2006: 59). Este rasgo permite el empleo de recursos literarios y lingüísticos como la elipsis, la condensación, la alusión, la anáfora, entre otros, los cuales estimulan la comprensión lectora del estudiante debido al grado de dificultad presentado en su corta extensión, pues se debe realizar un mayor esfuerzo de interpretación que en un texto más amplio.

La diversidad es la característica que permite al texto breve coincidir con diversos géneros ya que "la minificción es un género híbrido no sólo en su estructura interna, sino también en la diversidad de géneros a los que se aproxima" (Zavala, 2006: 60-61). La naturaleza híbrida de este prototipo textual permite su adaptación en variadas estrategias pedagógicas, pues combina particularidades externas e internas de otros géneros literarios como lenguaje figurado y diálogos.

El relato conjunta tres elementos: el conflicto, los personajes y la interacción de ambos. Su forma de relacionarse constituye la estructura narrativa (planteamiento, desarrollo, clímax y desenlace). De esta manera, el autor dirige al lector hacia el conocimiento de la vida y la mente de los personajes. Así se crea la empatía entre lector y personajes, en la cual interviene la visión interior de la obra y la visión exterior del lector, vinculación denominada por Bruner (2012) panorámica dual y por Zavala (2006) complicidad. La diversidad temática y estructural de creaciones breves genera diferentes grados de identificación de los lectores con lo narrado en los minicuentos.

El goce estético contribuye a esa complicidad porque el lector establece un vínculo más estrecho con el contenido del texto mediante la sensibilidad, la cual lleva a la experiencia de lectura: "La experiencia sería lo que nos pasa. No lo que pasa sino lo que nos pasa" (Larrosa, 2003: 28). La unión del goce estético y experiencia de lectura conforman la complicidad lector-texto.

Leer de manera fragmentada se ha intensificado desde finales del siglo xx y también se presenta cotidianamente en la forma escrita. Ambos aspectos se conjuntan en la minificción; ésta es parte de una unidad pero, al mismo tiempo, posee independencia estructural y temática. Zavala llama a este fenómeno fractalidad. "Estos y otros muchos síntomas de las estrategias de lectura de textos muy breves nos llevan a pensar que el fragmento ocupa un lugar central en la escritura 
contemporánea" (Zavala, 2006: 67). La aportación más importante de la fractalidad es que el lector puede construir una totalidad partiendo de fragmentos, los cuales pueden ser estudiados de manera individual ya que aportan detalles intrínsecos a la unidad textual.

La fugacidad del minicuento se refiere a su corta duración en el acto de lectura, lo cual permite un análisis más profundo y detallado de sus estructuras interna y externa en el aula. Además, se presenta de forma continua en los espacios virtuales. Aquí, el lector participa de una manera más directa en la creación y utilización del lenguaje del texto breve y en la elaboración de interpretaciones, por el contacto cotidiano con las formas contemporáneas de la tecnología. "El paso del texto al cibertexto es similar al de la lectura sobre el papel a la intervención en el hipertexto interactivo sobre la pantalla de la computadora" (Zavala, 2006: 71). La virtualidad es la característica del minicuento que se ha posicionado a través de los medios electrónicos. Su facilidad de difusión se ha incrementado con la creación de plataformas donde la colaboración del alumno puede diseminarse en diferentes roles.

Para Noguerol la minificción es como una espectrografía: "representaciones de la palabra intensificada por sus huecos" (Noguerol, 2011: 2). Ella explica que el género breve se caracteriza por sus silencios, los cuales se presentan mediante los espacios en blanco y los juegos del lenguaje en pocas grafías. Estos recursos funcionan a manera de huecos que el receptor debe llenar y puede completar la información no dicha en la historia.

La lectura de un texto tiene múltiples interpretaciones y las diferentes formas de leer establecen diferencias entre lo que Bruner (2012) denomina el texto real y el texto virtual. El primero se refiere al texto que permanece igual, el escrito original; el segundo es el resultado del acto de lectura. Cada individuo forma su propio texto a partir de su lectura.

Los textos narrativos utilizan formas del discurso que estimulan la imaginación del lector, quien produce significados a partir del texto y genera su propio texto virtual. Para ello debe existir la presuposición: "creación de significados implícitos en lugar de significados explícitos" (Bruner, 2012: 37). Lo implícito permite que el lector tenga libertad interpretativa porque descifra y atribuye significados al texto, según su contexto cultural y sus conocimientos previos.

Las técnicas que aportan amplitud de significado en la narrativa breve son variadas. Noguerol (2011) resalta dos: la recurrencia en el uso de signos de puntuación y la utilización de figuras retóricas de omisión. Ambos mecanismos crean algún sentido específico que el receptor abstrae y descifra durante el acto de lectura, estimulando su capacidad interpretativa.

El lector se encuentra ante un mundo de diversas posibilidades brindadas por el texto para atribuir significado (Bruner, 2012). El discurso literario emplea enunciados implicativos, los cuales incrementan la tensión narrativa porque el receptor completa la información que no le otorga el texto. De esta manera se convierte en cómplice de los personajes que interactúan en la historia y establece significados para comprender el texto mediante su propia interpretación. 
Los programas de investigación, promoción e intervención social para la mejora de habilidfades de lectocomprensión en la Región Ameca Jalisco en CUValles, Universidad de Guadalajara

El minicuento representa una posibilidad de lenguaje indirecto que conduce a una serie de percepciones únicas en cada lector. De esta manera, la minificción "está en el relator y en el lector, y no ya en el texto" (Pollastri, 2008). Esta situación conlleva a la creación de un mundo posible en la mente del receptor, quien construye la historia sin necesidad de que el texto muestre toda la información.

Acerca de los espacios, Noguerol (2011) resalta su función como silencios; éstos presentan dos características definidas: una página de extensión y las estructuras cerradas y compactas, las cuales marcan el ritmo del texto. Además, el silencio está inmerso en los personajes, hecho que resalta la frecuente presencia de espectros y fantasmas como protagonistas de los textos. De manera asidua los personajes del relato breve están relacionados con seres invisibles que convierten al texto en un enigma por descifrar.

La creación de mundos se construye a partir de otros mundos fabricados por otros. El sujeto parte de realidades ya planteadas que la preceden o que se están construyendo en ese momento. Esto implica, según Goodman (1974), que la creación de mundos posibles se realiza por la transformación de otros mundos y las versiones de éstos ya hechas. En relación con la psicología del desarrollo, el lector asigna "diferentes significados al mismo 'suceso' en edades diferentes" (Bruner, 2012: 104-105). Así, el lector traslada características de otros mundos anteriores conocidos por él de forma previa.

Noguerol (2011) afirma que el texto breve presenta individuos reactivos. Por lo general, se encuentran personajes que reaccionan a determinadas circunstancias sin que ellos originen alguna acción. Así, el receptor debe esforzarse más en interpretar los acontecimientos vertidos en la historia. Estas características favorecen y permiten el uso de la minificción como prototipo textual y género literario en el aula.

La escuela ha sido considerada como la institución que posee la legitimidad para enseñar y aprender las competencias lectoras. Se encarga de que los sujetos utilicen la lectura en sus funciones sociales, las cuales se resumen en tres usos: la adaptación a una sociedad urbana mediante su uso constante en la vida cotidiana, la potenciación del conocimiento y el acceso a la experiencia literaria (Colomer, 1997). De esta forma, las aulas son foros culturales, espacios donde los sujetos discuten, comparten conocimientos y todas aquellas actividades que impliquen comunicar, reflexionar y retroalimentar conocimientos entre individuos pertenecientes a un mismo grupo (Bruner, 2012).

Un foro cultural proporciona técnicas para incrementar la función participativa de los estudiantes, la cual reside en ser miembros activos y no sólo espectadores: "casi todo el aprendizaje en casi todos los marcos es una actividad comunal, un compartir cultura" (Bruner, 2012: 132). Para lograr que el alumno negocie e interprete la información es fundamental que el profesor comparta el material educativo adecuado. 
La clase, según Añez Medina (2008) es una "comunidad hermenéutica" pues a todo texto le es asignado un sentido por la aceptación social: necesita la aceptación colectiva. La escuela es un espacio donde el hecho literario se redefine y donde se pueden establecer valores en la sociedad y en la cultura que trasciendan a través del tiempo, los cuales son transmitidos según intereses de grupos hegemónicos.

Para Bruner (2012) el estudio de las obras literarias debe dirigirse hacia la comprensión del porqué causan efectos determinados en el receptor. El lenguaje literario requiere de formas simbólicas para expresarse. En particular, la narrativa se rige por la intención, la cual es identificada por el receptor gracias a la inmediatez que ella supone y su reconocimiento no requiere interpretaciones complejas sino que cada sujeto utiliza sus instrumentos culturales y sus experiencias para atribuir un significado al texto.

\section{La minificción como estrategia didáctica}

Las estrategias didácticas en el contexto educativo se han modificado a través del tiempo debido a variados factores como el desarrollo acelerado de la tecnología, la proliferación de los medios audiovisuales y la forma en que los sujetos aprenden en estas circunstancias. Los cambios en las necesidades institucionales y ambientes de aprendizaje han propiciado que la literatura se utilice cada vez más como estrategia didáctica en el aula universitaria (Zavala, 2006).

Desde la novela convencional hasta el aforismo, las formas de creación muestran versatilidad estructural y variedad temática. Entre esa multiplicidad de obras literarias que el docente puede emplear como material didáctico se ha difundido la minificción, género de reciente difusión en la historia literaria. Sus antecedentes en México datan de principios del siglo xx y ha tenido mayor auge en Hispanoamérica. Su vinculación con las vanguardias y las formas postmodernas han motivado su análisis académico (Zavala, 2006).

El minicuento es un género literario considerado innovador por sus características literarias y lingüísticas. "Son textos cuya extensión raramente rebasa una página impresa, y cuya complejidad y riqueza literaria ha llamado la atención de los lectores en todo el mundo" (Zavala, 2006: 7). Por estas razones, la aplicación de este género en la educación ha comenzado a tomar mayor importancia, pues representa una alternativa actual para la enseñanza.

La minificción como subgénero narrativo de reciente boga en el mundo literario se ha podido insertar en las aulas universitarias debido a rasgos como la brevedad, la ironía, la intertextualidad y la hibridación. Una de sus particularidades es la sorpresa, elemento fundamental para comprender cómo los lectores construyen sus mundos posibles. Se basa en la presuposición, pues el lector espera algo determinado del texto y luego existe una reacción ante lo inesperado. Bruner (2012) explica este proceso como el ingreso de estímulos en el sujeto. Si los estímulos coinciden con la expectativa del lector, éste continúa la lectura con el modelo que había fabricado en su mente desde una perspectiva que para él es correcta. 
Los programas de investigación, promoción e intervención social para la mejora de habilidfades de lectocomprensión en la Región Ameca Jalisco en CUValles, Universidad de Guadalajara

La difusión del minicuento es beneficiada por las redes sociales, las cuales fungen como catapulta para crear espacios de reflexión. La hiperbrevedad proporciona un gran impacto en los receptores y es una forma de la literatura contemporánea que se acerca más a los estudiantes.

Como forma narrativa contemporánea, las minificciones podrían compararse con un iceberg porque sólo se percibe la parte superficial, las restantes existen pero se encuentran en la estructura profunda y no se identifican con facilidad (Rojo, 1996). Por ello, la utilización actual de las minificciones en el aula se presenta con más asiduidad, pues existen textos breves que en apariencia no tienen argumento porque éste se presenta en el nivel profundo; se necesita un lector que lo descubra para darle sentido. El alumno se convierte en el actor principal del proceso de interpretación al otorgar un significado determinado a este tipo de obras literarias.

La minificción es una opción de recurso didáctico que poco a poco está siendo reconocido en el ámbito educativo. Zavala (2006) sugiere la inclusión de este subgénero como recurso didáctico y reconoce que éste empieza a ser más difundido por su importancia literaria y por la aceptación de los lectores, quienes han ido afianzándose con mayor intensidad a diversas muestras de creación y estudio de este género.

\section{Conclusiones}

El uso de habilidades desarrolladas en los espacios cotidianos de comunicación donde predomina el uso de las plataformas virtuales ha sido trasladado al ámbito escolar por los alumnos, quienes demandan formas de enseñanza que impliquen la literacidad electrónica.

Desde esta perspectiva, los sujetos buscan descubrir significados mediante diferentes vías y espacios, incluida el aula. Esta inquietud conlleva a la elaboración de nuevas formas para seguir expresando diferentes maneras de significar. Así, emerge la creación de mundos posibles que los sujetos construyen a partir de la lectura de textos literarios.

La literatura desarrolla en el lector la apreciación y el discernimiento. Cualquier obra literaria puede ser comprendida y disfrutada por cualquier lector en cualquier momento gracias a su confrontación lectora, compuesta por su gusto particular y apreciación personal (Añez Medina, 2008).

En los relatos, los personajes, los ambientes y las acciones son determinados por las transacciones culturales, ya que éstas delimitan lo permisible y lo comprensible; originan diversos mundos posibles y múltiples roles adjudicados a los personajes. Los lectores exponen sus interpretaciones y comparten los diferentes significados atribuidos según su propia visión del mundo, la cual es conformada por la raza, la etnia y el género, factores que inciden en las maneras de observar y de expresar la realidad.

En el aula, la lectura requiere de la comunicación entre profesor y alumnos, quienes comparten conocimientos y percepciones de los textos que enriquecen la visión individual de cada miembro. Así, el estudiante, a partir de sus conocimientos previos y de las perspectivas aportadas por los miembros del grupo, otorga un significado al texto. 
Mónica Almeida López, Rachel Garcíaeres, Reynaga, Hilde Aquino, Teresa Orozco. Colaboradores: Pablo Silva Villalever y Víctor Montero Gaytán

Los rasgos de la minificción permiten que su lectura sea compartida en el aula: su amplitud de interpretación invita a los alumnos a compartir los diversos sentidos atribuidos al texto, conformándose así una práctica de lectura. Kalman postula que "las personas acceden a las prácticas sociales de lectura y escritura porque participan en su uso con quienes las conocen y utilizan" (Kalman, 2003: 9). El uso y la circulación de los materiales escritos promueven la lectura. En este sentido, los alumnos participan en la lectura de minificciones en el aula porque existe un sujeto que los motiva y los guía en la apreciación del texto. Por esta razón el papel del maestro es fundamental en el proceso lector en el aula.

El uso de la minificción como medio para acercar a los estudiantes a la lectura se está convirtiendo, cada vez más, en una opción utilizada en el aula. Este género literario representa una línea de estudio que puede explotarse aún más en el ámbito literario y es un campo fértil para la investigación educativa como recurso metodológico o aporte a las temáticas de la lectura y la escritura.

\section{Referencias}

Añez Medina, A. (2008). "Literatura: (dis)curso y (des)orden”. Omnia, 14(3), 75-88, pp.75-88. Recuperado de:

http://www.redalyc.org/articulo.oa?id=73711121004

Bruner, J. (2012). Realidad mental y mundos posibles. Los actos de la imaginación que dan sentido a la experiencia. México: Gedisa.

Caro Salcedo, L. C. y N. C. Arbeláez Echeverri (2009). "Hipertextualidad, literacidad y discurso académico: conceptos para la gestión del conocimiento en la red". Revista Virtual Católica del Norte (28), pp. 1-23. Recuperado de:

http://www.redalyc.org/articulo.oa?id=194214468007

Chartier, R. (2000). Entre poder y placer. Cultura escrita y literatura en la edad moderna. Madrid: Cátedra.

Caldera de Briceño, R. V., D. T. Escalante de Urreacheaga y M. Terán de Serrentino (2011). "La lectura en el medio escolar: una experiencia pedagógica". Educere, 15 (51), pp. 451-462. Recuperado de: http://www.redalyc.org/articulo.oa?id=35621559015

Colomer, T. (1997). "La enseñanza y el aprendizaje de la comprensión lectora". Signos, teoría y práctica de la educación (20), pp. 6-15. Recuperado de:

http://www.quadernsdigitals.net/index.php?accionMenu=hemeroteca.VisualizaArticuloIU. visualiza\&articulo_id $=683$

Córdova, D., K. Ochoa y M. Rizk (2009). "Concepciones sobre la enseñanza de la lectura en un grupo de docentes". Investigación y Postgrado, 24 (1), pp.159-187. Recuperado de: http:// www.redalyc.org/articulo.oa?id $=65815763007$ 
Los programas de investigación, promoción e intervención social para la mejora de habilidfades de lectocomprensión en la Región Ameca Jalisco en CUValles, Universidad de Guadalajara

González, R., M. Guízar, I. Sepúlveda y L. Villaseñor (2003). "La lectura: vinculación entre placer, juego y conocimiento". Revista Electrónica Sinéctica (22), pp. 52-57. Recuperado de: http:// www.redalyc.org/articulo.oa?id $=99817932008$

Goodman, N. (1974). Los lenguajes del arte. Barcelona: Seix Barral.

Goodman, K. (1989). "El proceso de lectura: consideraciones través de las lenguas y el desarrollo". E. Ferrero y M. Gómez (eds.). Nuevas perspectivas sobre el proceso de lectura y escritura. México: Siglo XXI.

Kalman, J. (2003). "El acceso a la cultura escrita: la participación social y la apropiación de conocimientos en eventos cotidianos de lectura y escritura". Revista Mexicana de Investigación Educativa, 8 (17), pp. 37-66 Recuperado de: https://www.uam.es/otros/fmee/documentos/kalman_fmee.pdf

Larrosa, J. (2003). La experiencia de la lectura. México: Fondo de Cultura Económica.

Lemos Vóvio, C. (2008). "Las prácticas de lectura en la alfabetización de jóvenes y adultos: ¿qué se tiene que aprender y qué se tiene que hacer?". Decisio, pp. 13-17. Recuperado de:

http://tumbi.crefal.edu.mx/decisio/images/pdf/decisio_21/decisio21_saber2.pdf

Macías Andere, V. y G. López Hernández (2013). "Lectura: historia y promoción”. En: A. Ávila, A. Carrasco, A. Gómez, M. Guerra, G. López y J. L. Ramírez (coords.). Una década de investigación educativa en conocimientos disciplinares en México. Matemáticas, ciencias naturales, lenguaje y lenguas extranjeras. 2002-2011. (pp. 369-378). México: ANUIES-COMIE.

Márquez Montes, E. (2010). “Una experiencia de mediación de lectura, para 'otros lectores'”....Educere, 14 (48), pp. 45-51. Recuperado de: http://www.redalyc.org/articulo.oa?id=35616720005

McInerney, D. (2005). "Educational Psychology-Theory Research and Teaching: 25-Years Retrospective". Educational Psychology, vol. 25, núm. 6, diciembre 2005, pp. 585-599.

Noguerol, F. (2011). "Espectografías: minificción y silencio". Lejana. Revista Crítica de Narrativa Breve, núm. 3, pp.1-15.

Nieto, A. (2003). Leer es hacer el amor con la vida. Congreso Lectura 2003, celebrado en La Habana, Cuba. Extraído el 22 de abril de 2004 de: http://64.233.161.104/ search?q=cache:Jr5F1suFvacJ:www.cerlalc.org/reflexiones_p/Cuba.doc+Nieto+lectura + raz $\% \mathrm{C} 3 \% \mathrm{~B} 3 \mathrm{n}+$ emociones + paradigmas $\& \mathrm{hl}=\mathrm{es})$

Petit, M. (2001) Lecturas: del espacio íntimo al espacio público. México: Fondo de Cultura Económica.

Pollastri, L. "La figura del relator en el microrrelato hispanoamericano". Irene Andres-Suárez y Antonio Rivas (eds.). La era de la brevedad. El microrrelato hispánico. Palencia: Menoscuarto, 2008, pp.159-182.

Rojo, V. (1996). Breve manual para reconocer minicuentos. Caracas: Equinoccio.

Sánchez, C. e Y. Chacón Contreras (2006). "Lectura: una experiencia sublime”. Educere, 10 (33), pp.279-282. Recuperado de: http://www.redalyc.org/articulo.oa?id=35603311 
Mónica Almeida López, Rachel Garcíaeres, Reynaga, Hilde Aquino, Teresa Orozco. Colaboradores: Pablo Silva Villalever y Víctor Montero Gaytán

Sanjuán Álvarez, M. (2011). "De la experiencia de la lectura a la educación literaria. Análisis de los componentes emocionales de la lectura literaria en la infancia y la adolescencia". Ocnos: Revista de Estudios sobre Lectura, (7), pp. 85-99. Recuperado de: http://www.redalyc.org/ articulo.oa?id=259122665007

Solé, M. (2007). "Consideraciones didácticas para la aplicación de estrategias de lectura". Revista Electrónica Actualidades Investigativas en Educación, 7 (3), pp. 1-15. Recuperado de:

http://www.redalyc.org/articulo.oa?id=44770306

Smith, F. (1990). Para darle sentido a la lectura. Madrid: Visor.

Yubero Jiménez, S. y E. Larrañaga Rubio (2010). "El valor de la lectura en relación con el comportamiento lector. Un estudio sobre hábitos lectores y estilo de vida en niños". Ocnos: Revista de Estudios sobre Lectura, (6), pp.7-20. Recuperado de: http://www.redalyc.org/articulo. oa? $\mathrm{id}=259119721001$

Vaca Uribe, J. E. (2003). "Las unidades de procesamiento en la lectura infantil de textos". Revista Mexicana de Investigación educativa, 8(17), pp.99-124. Recuperado de http://www.redalyc. org/pdf/140/14001706.pdf

Zavala, L. (2006). La minificción bajo el microscopio. México: UNAM.

Recibido: 30/01/15

Dictaminado: 22/06/15

Corregido: $14 / 09 / 15$

Aceptado: 15/og/15 